\title{
Advancing biomimetic materials through ISO standards
}

1 Norbert Hoeller $B S C_{1}^{*}$

Independent Researcher, Sustainable Innovation Network, Stouffville, ON, Canada
2 Filippo A. Salustri PhD, Peng

Associate Professor, Ryerson University, Toronto, ON, Canada
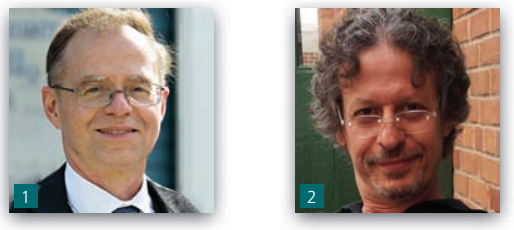

Q2 This paper discusses the challenges and opportunities of developing standards for biomimetic materials, based on the authors' experience with International Organization for Standardization (ISO)/Technical Committee 266 'Biomimetics'. With the expansion of global trade, international standards are increasingly called on to protect the interests of consumers, improve business productivity and facilitate trade. In the past, standards typically addressed form/fit/function specifications and were associated with mature industries. Recently some ISO standards are focusing on processes, quality and consistency, which can support advances in emerging fields. ISO has the potential to advance biomimetic materials and biomimetics in general by developing and promoting frameworks that reflect the evolving nature of biomimetics.

\section{Q3 1. Introduction}

The International Organization for Standardization (ISO) ${ }^{1}$ was launched in 1947 to 'ensure that products and services are safe, reliable and of good quality' across the world. It is the leader in writing international standards, with over 19500 publications developed through the support and collaboration of 160 member countries. In addition to benefiting consumers, standards play an important role in increasing business efficiency and reducing global trade barriers.

Despite the exponential growth of biomimetic patent filings since $1985^{2}$ and similar trends in academic publications, ${ }^{3}$ there have been few ISO initiatives in the area of biomimetics, biomimicry and bio-inspired design. The ISO Technical Committee (TC) ISO/TC 229 'Nanotechnologies' was launched in 2005 - although its business plan ${ }^{4}$ mentions the importance of biology, to date, the TC does not appear to have addressed biomimetic aspects specifically. ISO/TC 276 'Biotechnology'5 was launched in 2013 but does not mention biomimetics directly.

\section{Background of ISO/TC $\mathbf{2 6 6}$}

ISO launched TC 266 'Biomimetics' in October 2012 to develop an international consensus on standards relating to biomimetics. ${ }^{6}$ The key objectives ${ }^{7}$ included
- improving communications through standardized terminology

- describing the potential and limitations of biomimetics in the areas of innovation and sustainability

- facilitating interdisciplinary initiatives that translate biological research into technical products

- improving international co-operation.

The German Verein Deutscher Ingenieure (VDI, or Association of German Engineers $)^{8}$ provided a number of documents as working drafts for three initial Working Groups (WGs)

- WG 1: 'Biomimetics - terminology, concepts and methodology', based on VDI $6220^{9}$

- WG 2: 'Biomimetics - biomimetic materials, structures and components', based on VDI $6223^{10}$

- WG 3: 'Biomimetics - biomimetic structural optimization', based on VDI 6224 part $1^{11}$ and VDI 6224 part $2 .{ }^{12}$

In May 2013, ISO/TC 266 approved Japan's proposal to create WG 4 'Knowledge infrastructure of biomimetics', initially as a research project that would lead to an official ISO/TC 266 project.

\section{Status of ISO/TC 266}

There are currently ten participating countries (Belgium, Canada, China, Czech Republic, France, Germany, Israel, Japan, Switzerland, 
Bioinspired, Biomimetic and Nanobiomaterials Volume XXXX Issue BBNXXXX
Advancing biomimetic materials through

ISO standards

Hoeller and Salustri
UK) and 14 observing countries (Argentina, Denmark, Finland, Hong Kong, India, Iran, Kazakhstan, Republic of Korea, Malaysia, Netherlands, Poland, Serbia, Sweden, Thailand). ISO/TC 266 meetings were held in Berlin (2012), Paris (2013), Prague (2013), Liège (2014) and Kyoto (2015).

In May 2015, WG 1 published ISO $18458,{ }^{13}$ including a limited terminology, basic concepts, the rationale for biomimetics, a methodology modeled on engineering and a discussion of the relationship of biomimetics to innovation. A key component was a set of criteria for biomimetic products along with their application to a set of case studies. Also in May 2015, WG 3 published ISO $18459,{ }^{14}$ which explored the application of self-optimization principles from nature to computer-aided optimization, soft kill option, computer-aided internal optimization and method of tensile triangles. Both WGs have disbanded since they have no official active projects. Canada is working on a Biomimetic Assessment Framework that expands on the ISO 18458 criteria but was not ready to submit a formal proposal at the Kyoto meeting. WG 2 will be holding a final vote shortly on ISO $18457,{ }^{15}$ and it is expected to disband once that task is complete. In May 2016, WG 4 submitted a formal ISO project proposal to develop recommendations for an ontology-enhanced thesaurus.

\section{WG 2: biomimetic materials, structures and components}

WG 2 was created specifically to explore biomimetic materials. The WG 218457 document is in the Final Draft International Standard (FDIS) stage. It includes an extensive list of characteristics associated with biological materials. The characteristics are organized into two broad classes: properties and manufacture. Whereas technological materials tend to be designed for a single function, have-a high durability and have a limited adaptability, biological materials tend to be multifunctional, have a limited life span and have a degree of adaptability through growth and structural changes.

FDIS_1 18457 describes an extensive set of biological material properties organized under materials, process, 'self-X', sensors, hydrodynamics, saving energy/resources, adaptability and behavior/ ecology. Biological examples are referenced, as well as potential application areas by industry sector. The document also emphasizes the importance of structure, particularly hierarchy at a broad range of scales.

FDIS 18457 highlights the importance of exploring analogies between the technical target system and a suitable biological model identified through biomimetic research. In addition to describing the analysis, abstraction and material selection phases, it documents a series of tests to determine the compatibility of the biological model to the technical system in areas such as functionality, relevance of key parameters, parameter ratios and factors and quality criteria. Although biological solutions often need to be taken out of their original context when adapted to technical systems, understanding clearly the differences in context can increase the likelihood of success.
The document includes examples of biomimetic materials and structures including biologically inspired polymers, biomimetic micro-/nanostructures emulating mother-of-pearl, interference pigments, self-sharpening tools, structures emulating plant stems, orthopedic screws based on computer-aided optimization, 'bottom-up' manufacturing methods, structural color, antireflective surfaces, reversible adhesives based on gecko setae and selfcleaning surfaces.

Lastly, FDIS 18457 provides an overview of analytical methods suitable for exploring the different characteristics of biological materials. The methods are organized by purpose, including

- morphology/structure

- mechanical, optical and other physical properties

- chemical characteristics

- behavior analysis

- biological characterization and activity.

\section{Challenges and opportunities}

The international reputation of ISO can help attract experts who might otherwise not participate. However, despite the high degree of interest in biomimetics, ISO/TC 266 has attracted limited international participation. ${ }^{16}$ Until mid-2014, there was no representation from the Americas. Even within Europe, countries such as the Netherlands that are leaders in biomimetics are not actively participating members. A major challenge is the high cost imposed by some national standards organizations that accredit WG experts and heads of delegation. ${ }^{17}$ ISO's strict copyright restrictions also limit involvement by experts who are not identified as WG members from participating countries. One option is to engage the broader international community in developing working drafts and building an international consensus prior to formally launching official ISO/TC projects.

ISO's focus on improving business efficiency and facilitating global trade helps attract representation from industry, business and regulators. ISO/TC 266 has had difficulty engaging experts from these groups, important for developing deliverables that can help further the adoption of biomimetics as well as cover the fees charged by national standards organizations. The onus is on the participating countries to identify key national stakeholders, identify their needs and encourage them to participate in ISO projects. Another opportunity is to leverage liaisons with other ISO TCs, identifying opportunities where biomimetics could enhance their projects and conversely tap their business expertise.

Due to the overheads involved in developing ISO deliverables, the process works best when a preliminary consensus in a subject area already exists. Discussions among the ISO/TC 266 WG experts reveal a wide range of perspectives on the scope, characteristics and practice of biomimetics. In some cases, even basic terms have different meanings within the community. Encouraging a discussion of biomimetics, biomimicry and bio- 
Bioinspired, Biomimetic and Nanobiomaterials Volume XXXX Issue BBNXXXX
Advancing biomimetic materials through

ISO standards

Hoeller and Salustri inspired design that focuses on common characteristics would improve communication and collaboration both inside ISO and within the broader community. ${ }^{18}$ ISO/TC 266 could support this goal by developing and publishing a vocabulary including a broad set of internationally accepted terms and definitions. An example of such a vocabulary is ISO/TC 229's ISO/Technical Report (TR) 11360:2010 'Nanotechnologies - methodology for the classification and categorization of nanomaterials', which not only defines key nanotechnology concepts but also adds insight by revealing the relationships between concepts through a tree structure. ${ }^{19}$

ISO has been traditionally associated with prescriptive standards that are suitable for mature fields but may restrict emerging fields unnecessarily. One challenge of creating a set of general standards for biomimetics is the applicability of the standards across the multitude of ways that biomimetics is applied in various sectors.

Q4 Unlike Leadership in Energy and Environmental Design, which is used in the built environment, and Cradle to Cradle, which targets product design, biomimetic processes are used in both of these applications as well as materials science, computing, organizational design and social innovations. The creation of standards that can span this wide array of applications remains a challenge within ISO/TC 266. There is a growing interest in a different kind of standard that addresses systemic challenges or relationships rather than specific characteristics and performance of the artifacts themselves. Two examples are ISO 9000 (Quality Management) $^{20}$ and ISO 14000 (Environmental Management). ${ }^{21}$ Although there is no crisp definition for this type of standard, the focus tends to be on the process of how artifacts are created rather than the specific characteristics and performances of the artifacts themselves. The challenge is defining a framework acceptable to the broader community that accelerates development of the field while also encouraging creativity and experimentation.

Although interdisciplinary collaboration is a cornerstone of biomimetics, studies suggest that collaboration is not pervasive in either practice ${ }^{22}$ or research. ${ }^{23}$ Interest in biomimetics is often driven by people's fascination with nature and natural phenomenon. An alternative approach is to seek actively the intersection of compelling industry needs with emerging biomimetic capabilities. For example Gleich et al. ${ }^{24}$ highlighted the growing challenges of logistics management due to increasing complexity. At the same time, biomimetic optimization strategies are becoming better understood and documented, to the point where they are close to achieving an appropriate level of technology readiness. ${ }^{24}$ ISO/TC 266 could identify intersections between needs and capabilities that create opportunities for action research projects that deliver practical solutions while at the same time advancing fundamental research.

The relationship of biomimetics and sustainability continues to be debated. Some claim that applying concepts learned from nature will lead inherently to greater efficiency and thereby increase sustainability. ${ }^{25}$ Others argue that sustainability requirements need to be incorporated explicitly in all phases of the design process. ${ }^{26}$ The biomimetic promise of sustainability assumes that the technological innovation is close to the biological source in both features and context. However, biomimetic innovation often transfers only selected features and is implemented in a different context, weakening the argument that the solution has been 'tried and tested'. ${ }^{24}$ ISO/TC 266 has an opportunity to incorporate sustainability metrics into biomimetic assessments and explore the relationship of biomimetics to the sustainability sector and business trends.

\section{Conclusion}

ISO can advance emerging fields such as biomimetic materials so long as it does not constrain further development by prescribing tools and methods prematurely. ISO WGs can

- facilitate international collaboration by attracting a more diverse group of experts

- establish a 'common ground' within the community by developing agreement on a common vocabulary and high-level goals

- identify key industry sectors and stakeholders

- analyze and document sector needs and trends

- identify key initiatives and outcomes that standards can help advance.

ISO WGs can promote collaboration between the industry and the academia to explore key opportunities. For example failure mechanisms in biological materials have been studied extensively ${ }^{27}$ but the implications have yet to be realized fully in technological materials, such as leveraging hierarchical structure, stiffness at the molecular level, spread deformation and sacrificial bonds. Preparing a comprehensive comparison of failure mechanisms in biological materials and identifying relevant unsatisfied technological needs could encourage industry/academia collaboration on projects that couple research with practical applications. Transdisciplinary teams can be particularly valuable in breakthrough innovation where exploring principles based on research on new phenomena is essential to properly recognizing and defining the technological need. $^{28}$

The challenge is providing a degree of structure to accelerate the evolution of the field while at the same time encouraging and incorporating diverse ideas. ISO recommends that new work item proposals be accompanied by well-developed working drafts these can be prepared outside of the ISO process, avoiding ISO copyright restrictions. If the working draft has already received broad international support, an accelerated 24-month ISO project timetable may be applicable. Lastly, it is important to choose the right ISO deliverable. Three of the four ISO deliverables ${ }^{29}$ are normative and more suitable for technologies and methods that are well understood and demonstrably robust. The $\mathrm{FP}_{1}^{30}$ is primarily informative and can encourage continuous development if it incorporates a mechanism for testing the concepts, gathering feedback and incorporating improvements. 
Bioinspired, Biomimetic and Nanobiomaterials Volume $X X X X$ Issue BBNXXXX
Advancing biomimetic materials through

ISO standards

Hoeller and Salustri
Although ISO can provide a framework for developing an international consensus and a platform for publishing deliverables, it is ultimately up to the international community working in conjunction with ISO to take a leadership role in mapping the biomimetic materials landscape, identifying industry trends and driving initiatives that will advance the field.

\section{REFERENCES}

1. ISO (International Organization for Standardization) (2016) http://www.iso.org/iso/home.html (accessed 27/03/2016).

2. Bonser RHC and Vincent JFV (2007) Technology trajectories, innovation, and the growth of biomimetics. Proceedings of the Institution of Mechanical Engineers, Part C: Journal of Mechanical Engineering Science 221(10): 1177-1180.

3. Lepora NF, Verschure P and Prescott TJ (2013) The state of the art in biomimetics. Bioinspiration \& Biomimetics 8(1): 013001.

4. ISO (2011) ISO/TC 229 Nanotechnologies Business Plan. ISO, Geneva, Switzerland. See http://isotc.iso.org/livelink/ livelink/fetch/2000/2122/687806/ISO_TC_229_ Nanotechnologies_pdf?nodeid $=6507632 \&$ vernum $=-2$ (accessed 24/03/2016).

5. ISO (2015) ISO/TC 276 Biotechnology Business. ISO, Geneva, Switzerland. See http://isotc.iso.org/livelink/livelink/ fetch/2000/2122/687806/ISO_TC_276_Biotechnology_.pdf? nodeid $=17046077 \&$ vernum $=-2$ (accessed 24/03/2016).

6. ISO (2013) Biomimetics boom calls for standards. In Q6 ISOfocus, 100: 24-25. See http://www.iso.org/iso/ isofocus_100.pdf (accessed 07/07/2014).

7. ISO (2013) ISO/TC 266 Biomimetics Business Plan. ISO, Geneva, Switzerland. See http://isotc.iso.org/livelink/livelink/ fetch/2000/2122/687806/ISO_TC_266_Biomimetics_pdf? nodeid=15630038\&vernum=-2 (accessed 24/03/2016).

8. VDI (The Association of German Engineers) (2016) http:// www.vdi.eu/ (accessed 28/03/2016).

9. VDI (2011) VDI 6220. VDI, Düsseldorf, Germany. See http:// www.vdi.eu/nc/guidelines/entwurf_alt_vdi_6220-bionik_ konzeption_und_strategie_abgrenzung_zwischen bionischen_und_konventionellen_verfahrenprodukten/ (accessed 24/03/2016).

10. VDI (2011) VDI 6223. VDI, Düsseldorf, Germany. See http:// www.vdi.eu/nc/guidelines/entwurf_alt_vdi_6223bionik_bionische_materialien_strukturen_und_bauteile/ (accessed 24/03/2016).

11. VDI (2012) VDI 6224 Blatt 1. VDI, Düsseldorf, Germany. See http://www.vdi.eu/nc/guidelines/vdi_6224_blatt_1bionische_optimierung_evolutionaere_algorithmen_in_der anwendung/ (accessed 24/03/2016).

12. VDI (2012) VDI 6224 Blatt 2. VDI, Düsseldorf, Germany. See http://www.vdi.eu/nc/guidelines/vdi_6224_blatt_2bionische_optimierung_anwendung_biologischer_ wachstumsgesetze_zur_strukturmechanischen/ (accessed 24/03/2016).

13. ISO (2015) ISO 18458:2015: Biomimetics - terminology, concepts and methodology. ISO, Geneva, Switzerland.
See http://www.iso.org/iso/catalogue_detail.htm? csnumber $=62500$ (accessed 27/03/2016).

14. ISO (2015) ISO 18459:2015: Biomimetics - biomimetic structural optimization. ISO, Geneva, Switzerland. See http://www.iso.org/iso/catalogue_detail.htm? csnumber=62501 (accessed 27/03/2016).

15. ISO (2015) ISO/DIS 18457: Biomimetics - biomimetic materials, structures and components. ISO, Geneva, Switzerland. See http://www.iso.org/iso/catalogue_detail.htm? csnumber=62499 (accessed 27/03/2016).

16. Pechstein A (2014) International standardization of biomimetic methods and approaches: ISO/TC-266. ISBE Newsletter 3(1): 14-15. See http://www.isbe-online.org/files/files/201411/ 20102923.pdf\#page $=14$ (accessed 24/03/2016).

17. Mead TL and Hoeller N (2014) The ISO/TC 266 Biomimetics Standard Initiative. Zygote Quarterly 10: 72-83. See http:// issuu.com/eggermont/docs/zq_issue_10_final/72 (accessed 24/03/2016).

18. Hoeller N, Goel A, Freixas C et al. (2013) Developing a common ground for learning from nature. Zygote Quarterly 7: 133-145. See https://www.academia.edu/13592692/Developing_a_Common _Ground_for_Learning_from_Nature (accessed 27/07/2015).

19. ISO (2010) ISO/TR 11360:2010: Nanotechnologies methodology for the classification and categorization of nanomaterials. ISO, Geneva, Switzerland. See http://www.iso. org/iso/iso_catalogue/catalogue_tc/catalogue_detail.htm? csnumber $=55967$ (accessed 27/03/2016).

20. ISO (2015) ISO 9000: Quality management. ISO, Geneva, Switzerland. See http://www.iso.org/iso/home/standards/ management-standards/iso_9000.htm (accessed 30/03/2016).

21. ISO (2015) ISO 14000: Environmental management. ISO, Geneva, Switzerland. See http://www.iso.org/iso/iso14000 (accessed 30/03/2016).

22. Jacobs SR, Nichol EC and Helms ME (2014) 'Where are we now and where are we going?' The BioM Innovation Database. Journal of Mechanical Design 136(11): 111101-111110, http://dx.doi.org/10.1115/1.4028171.

23. Snell-Rood E (2016) Interdisciplinarity: bring biologists into biomimetics. Nature 529(7586): 277-278, http://dx.doi.org/ $10.1038 / 529277$ a.

24. Gleich A, von Pade C, Petschow U and Pissarskoi E (2010) Potentials and Trends in Biomimetics, 1st edn. Springer Berlin, Germany.

25. Benyus JM (2002) Biomimicry: Innovation Inspired by Nature. William Morrow, New York, NY, USA.

26. Mead TL (2014) Biologically-inspired innovation in large companies: a path for corporate participation in biophysical systems? Design and Nature VII 9(3): 216-229. See http:// www.witpress.com/Secure/ejournals/papers/DNE090305f.pdf (accessed 07/06/2016).

27. Vincent JFV (1990) Fracture properties of plants. Advances in Botanical Research 17: 235-287.

28. Norman D (2010) Technology first, needs last. Interactions 17(2): 38-42. See http://www.jnd.org/dn.mss/technology_ first_ne.html (accessed 28/03/2016). 
Bioinspired, Biomimetic and Nanobiomaterials Volume XXXX Issue BBNXXXX
Advancing biomimetic materials through

ISO standards

Hoeller and Salustri
29. ISO (2012) ISO deliverables. ISO, Geneva, Switzerland. See http://www.iso.org/iso/home/standards_development/ deliverables-all.htm (accessed 29/03/2016).
30. ISO (2012) ISO/TR Technical Report. ISO, Geneva, Switzerland. See http://www.iso.org/iso/home/standards_development/ deliverables-all.htm?type $=\operatorname{tr}$ (accessed 24/03/2016).

\section{WHAT DO YOU THINK?}

To discuss this paper, please submit up to 500 words to the managing editor at journals@ice.org.uk.

Your contribution will be forwarded to the author(s) for a reply and, if considered appropriate by the editorin-chief, will be published as a discussion in a future issue of the journal.

ICE Science journals rely entirely on contributions sent in by professionals, academics and students coming from the field of materials science and engineering. Articles should be within 5000-7000 words long (short communications and opinion articles should be within 2000 words long), with adequate illustrations and references. To access our author guidelines and how to submit your paper, please refer to the journal website at www.icevirtuallibrary.com/bbn 


\section{Author Queries}

Q1: Please limit keywords to three only.

Q2: Please expand the abstract to 150 to 200 words.

Q3: Please verify that section headings have been assigned to the appropriate levels.

Q4: Please verify change of "LEED" to "Leadership in Energy and Environmental Design".

Q5: Please verify that " 013001 " is an article number. If not, please give complete page range for Ref. 3.

Q6: Please provide issue number for Ref. 6.

Q7: Please provide issue nos. for Refs. 17 and 18.

Q8: Please provide issue no. for Ref. 27. 